\title{
Stallard, Paul. (2010). Ansiedade: Terapia Cognitivo- Comportamental para crianças e jovens. Porto Alegre: Artmed.
}

DOI: 10.22289/2446-922X.V6N1A21

\author{
Nilson Antonio da Silva ${ }^{1}$ \\ Luciana de Araújo Mendes Silva \\ Arthur Siqueira de Sene
}

O autor da obra aborda a temática ansiedade a partir de sua definição básica, seus efeitos e processos disfuncionais, bem como sinaliza tratar-se de um transtorno comum a crianças e jovens. O livro é organizado em 12 capítulos, os quais abarcam desde os problemas de ansiedade na infância, passando pelo comportamento parental, à avaliação de problemas, manejo de emoções até os processos de resolução de problemas e prevenção de recaídas.

O autor inicia o livro discutindo, nos primeiros dois capítulos, sobre os problemas de ansiedade em crianças, em especial, aquelas que tendem a se preocuparem de maneira acentuada. Na infância, a preocupação está, geralmente, relacionada ao desempenho escolar, saúde, acidentes, danos pessoais e vínculos afetivos.

Em seguida, assegura que em uma pesquisa realizada no Reino Unido e nos Estados Unidos, verificou-se que $2 \%$ a $4 \%$ das crianças com idade entre 5 e 16 anos contemplam os requisitos para o diagnóstico de transtorno de ansiedade grave, conforme estabelece o Manual Diagnóstico e Estatístico dos Transtornos Mentais (DSM-IV).

Dentre os achados, o autor cita maior tendência do transtorno de ansiedade em crianças do sexo feminino em relação ao masculino, sendo que as primeiras apresentam mais possibilidades de relatar os sintomas relacionados ao transtorno. Além disso, há maior prevalência do transtorno de ansiedade conforme o aumento da idade da criança. Por ser tratar de uma obra internacional, não apresenta, em suas descrições, índices referentes à população brasileira.

A obra faz referência a algumas pesquisas longitudinais, que apontam uma tendência, na infância, dos transtornos de ansiedade permanecerem na idade adulta e que há relação dos fatores biológicos, ambientais e individuais, além dos elementos genéticos e características do temperamento que potencializam a vulnerabilidade desta patologia.

Stallard garante que, no transtorno de ansiedade, podem aparecer comorbidades como a depressão e as ansiedades específicas e trata o transtorno de ansiedade de separação como sendo um transtorno específico da infância, com base nos critérios diagnósticos do DSM-IV e

\footnotetext{
${ }^{1}$ Endereço eletrônico de contato: nilsoncontabil@yahoo.com.br

Recebido em 14/05/2019. Aprovado pelo conselho editorial para publicação em 05/06/2020.

Rev. Psicol Saúde e Debate. Jul., 2020:6(1): 285-290
} 
denota as particularidades da terapia cognitivo-comportamental (TCC), com a explanação da metodologia aplicada e a estruturação detalhada da sessão.

Ao longo do primeiro capítulo, Stallard apresenta casos clínicos que tornam o texto mais claro e contribuem para que o leitor possa fazer uma análise dos sintomas e comportamentos típicos de cada transtorno.

Há, neste segmento, a abordagem do transtorno de ansiedade fóbico como um medo mal-adaptativo, que não obedece à idade cronológica, mas permanece por longos períodos e difere-se dos medos ditos normais da fase infantil.

Adiante, Stallard trabalha o conceito de fobia social/transtorno de ansiedade social, embasando-se no CID-10, e descreve este transtorno como corriqueiro na adolescência, quando estes indivíduos sentem medo excessivo de serem avaliados pelas pessoas, em ambientes que possam sofrer qualquer tipo de embaraço ou humilhação.

Nesta linha de raciocínio, há apontamentos sobre os ataques de pânico e ênfase na identificação e classificação do DSM-IV-TR em três tipos: inesperados, vinculados a situações e predispostos por situações. O texto destaca ainda o fato de que este transtorno é caracterizado por sintomas fisiológicos, intensos e recorrentes.

Stallard finaliza o capítulo sinalizando preocupação com o transtorno de ansiedade generalizada, uma vez que gera preocupações excessivas, de forma incontrolável, que podem estar relacionadas a eventos passados e/ou futuros, além dos sintomas fisiológicos e sugere que as avaliações devem ser minuciosas a fim de evitar erros no diagnóstico.

De acordo com o autor, um ponto em comum entre todos estes transtornos é a possibilidade de potencializar o risco de abuso de álcool na adolescência, com intuito de minimizar os sintomas da ansiedade.

A segunda seção da obra é destinada a apresentar pontos de relevância terapêutica, tanto no atendimento individual quanto em grupo, e aborda técnicas como a psicoeducação, reconhecimento e manejo das emoções, exposição, automonitoramento, dentre outras, destacando ainda a necessidade de engajamento dos pais neste processo psicoterapêutico.

Em sequência, no terceiro tópico do livro, o autor faz um relato sobre as cognições e os processos disfuncionais, bem como as características em crianças e jovens com transtorno de ansiedade que têm atenção seletiva para os estímulos ameaçadores e tendem a assimilá-los de forma mais rápida, porém, não há pesquisas significativas que mostrem as proporções entre as cognições positivas e cognições negativas.

No quarto capítulo, o autor destaca um fator relevante na observação sobre a fase infantil, que é o comportamento parental desadaptativo. Para Stallard, este controle excessivo dos pais em relação aos filhos, a negatividade, as crenças, podem prejudicar a autoeficácia e 
tendem a desencadear sintomas ansiogênicos nas crianças, impedindo-as de dominar seus problemas.

No decorrer desta subdivisão do livro, existe um destaque claro para a importância do desempenho de papéis dos pais durante o tratamento; primeiramente como facilitadores, na promoção das habilidades aprendidas fora das sessões e estímulo para que a criança as desenvolva. Em segundo lugar, como coterapeutas, pois os pais são incentivados a apoiar, monitorar e estimular a capacidade de enfrentamento do filho fora das sessões. E, por fim, como coclientes, em razão de aprenderem novas habilidades para lidar com as conflitivas familiares.

Sequencialmente, nos capítulos quinto, sexto e sétimo, Stallard menciona a relevância da entrevista clínica e seus vários modelos disponíveis para aplicação. Apresenta as informações que devem ser obtidas, não para preencher os critérios de diagnósticos, mas para analisar os sintomas de forma funcional e compreensiva, para que seja possível identificá-los de forma precoce e, assim, desenvolver meios para a manutenção e enfrentamento das dificuldades.

Neste ínterim, o autor discute a relação terapêutica como fator primordial na psicoeducação, pois é através dela que se estabelece a confiança e torna-se possível o encorajamento necessário para que a criança expresse, do seu jeito, a compreensão da ansiedade.

Destaca-se também, neste ponto do texto, a existência de inúmeros modelos de entrevistas clínicas estruturadas utilizadas no diagnóstico de diversos transtornos mentais, inclusive os associados à ansiedade, sendo que o autor critica seus constructos genéricos que acarretam uma avaliação superficial baseada apenas nos critérios do DSM.

A obra traz ainda uma explicação do modelo cognitivo básico da ansiedade e a aplicação da terapia cognitivo-comportamental, que envolvem três domínios centrais, sendo eles o cognitivo, emocional e comportamental e realça a importância da relação entre eles.

O autor expõe também que a formulação do problema, além de oferecer a hipótese clínica de forma explícita, determina o plano de tratamento e afirma que o primeiro passo para o envolvimento é que a criança reconheça o problema.

Ao longo da obra, o autor reconhece a importância da motivação da criança em mudar suas cognições em relação ao problema enfrentado, pois só assim, ela investirá em um processo ativo de mudança, caso contrário, sentimentos de insegurança e ambivalência podem dificultar o tratamento.

No que tange aos objetivos do tratamento, Stallard propõe um acrônimo para representálos: SMART (specific, mensurable, achievable, realistic e time-oriented) que, traduzidos para o português, significam que os objetivos precisam ser específicos, mensuráveis, realizáveis, realistas e orientados no tempo para que a criança seja capaz de compreendê-los. 
A formulação do caso fornece à criança e aos pais, de forma simples, informações que esses necessitam para o entendimento da ansiedade. Isso é essencial para a criança realizar suas mudanças, visto que este modelo clarifica o que perpassa entre o comportamento, pensamento e sentimentos.

Durante todo o tempo de explanação do texto, Stallard reforça a participação dos pais no processo terapêutico e afirma o quanto este vínculo capacita a criança em comportamentos mais corajosos para enfrentar suas dificuldades, porém, o autor alerta sobre os fatores parentais desadaptativos, nos quais os pais mostram-se controladores em excesso, são intrusivos, encorajam a esquiva em situações de medo, além de serem negativos e críticos. Com isso, as crianças podem desenvolver dificuldade nas competências para lidar com seus problemas.

O oitavo capítulo é dedicado ao reconhecimento e manejo das emoções, tendo em vista que a área emocional é compreendida como o ponto de partida para as intervenções de TCC. Esta parte traz ainda folhas de exercícios para serem trabalhadas com crianças durante as sessões. As atividades são ilustradas e retratam sinais de ansiedade, que auxiliam a criança a expressar fatos recentes que a deixaram assustada ou com medo, além de atividades para relaxamento.

Outro instrumento apresentado neste segmento são as 'escalas de classificação de ansiedade', usadas para quantificar os estados subjetivos através de recursos visuais os quais permitem classificar, monitorar e manejar as emoções. Estes exercícios são expostos de forma a propiciar alívio imediato ou em longo prazo, uma vez que, é, a partir do entendimento dos sentimentos ansiosos, que a criança aprende a manejá-los e, com isso, é capaz de engajar-se no processo e desenvolver suas cognições.

No nono capítulo, Paul Stallard esclarece que o aprimoramento cognitivo deve ser trabalhado a partir do momento em que a criança e seus familiares conseguem entender e manejar os sentimentos de ansiedade, ou seja, já são capazes de perceber a importância que os pensamentos têm em relação aos sentimentos ansiogênicos.

Sendo assim, ao adquirir o domínio cognitivo, a criança deve ter seus pontos fortes reforçados, além de ser encorajada a analisar seus pensamentos e a questionar as evidências de cada um, se são úteis ou inúteis, pois, enquanto os pensamentos úteis podem ser capacitantes, os pensamentos inúteis tendem a aumentar os níveis de ansiedade.

Nos antepenúltimo e penúltimo capítulos, há uma abordagem acerca das formas de resolução de problemas, exposição e prevenção de recaídas como parte final da intervenção terapêutica, que almeja através de questionamentos, o desenvolvimento de habilidades para a solução de problemas, enfrentamento das situações as quais causam medo ou são evitadas, realização de experimentos para testar crenças e reforço das novas tentativas de enfrentamento. 
O autor apresenta também propostas alternativas para trabalhar com problemas corriqueiros que possam aparecer durante o processo interventivo, como a desmotivação da criança, o contexto familiar que não apoia o processo terapêutico, ou até mesmo quando as atividades direcionadas para casa não são realizadas, visto que a TCC se utiliza do método colaborativo.

No último capítulo, Stallard expõe exemplos de exercícios e materiais didáticos capazes de auxiliar na compreensão da psicoeducação e despertar o interesse da criança a engajar-se na TCC, além de oferecer aos psicólogos um vasto campo para exploração das técnicas, uma vez que são encorajados a desenvolver seus próprios recursos e adaptar os materiais de acordo com os interesses da criança.

A presente obra apresenta-se como um material de apoio embasado em metodologias científicas de atuação clínica profissional através da terapia cognitivo-comportamental, demonstrando clareza na apresentação do tema, bem como pluralidade no seu aprofundamento. Desta forma, aos profissionais que destinam depreender conhecimentos específicos voltados para o público-alvo clínico infantil (crianças e adolescentes) a obra apresenta esta conexão de forma evidente.

O autor cita algumas pesquisas sobre a incidência de ansiedade em crianças e jovens, ressalta que acomete, em maior número, os indivíduos do sexo feminino em relação aos indivíduos do sexo masculino, porém chama atenção à inexistência de informações sobre esta disparidade.

Paul Stallard expõe, ao longo da obra, o transtorno de ansiedade de forma globalizada, sem se aprofundar em questões distintivas específicas de cada transtorno e sem desenvolver as particularidades de cada faixa etária.

Destaca-se também que a obra contempla a apresentação de uma gama de materiais para utilização durante as sessões, bem como há a exposição, pelo autor, em meio aos capítulos, de exemplos de casos clínicos, o que colabora para a ampliação do entendimento teórico e prático.

A obra notabiliza-se em oferecer sugestões de técnicas da terapia cognitivocomportamental para atendimento de crianças e jovens com sintomatologia de ordem ansiogênica. Tais técnicas caracterizam-se por sua fácil aplicação, com possibilidade de adaptação de acordo com a necessidade e individualidade de cada paciente.

Paul Stallard constrói um material de relevância ao tema ansiedade, indicado aos profissionais e estudantes de psicologia que podem se aproveitar dos conhecimentos técnicocientíficos e potencializar, de forma direcionada, o auxílio a tal público-alvo. O material pode também ser usado como apoio a profissionais da saúde de maneira geral que estejam inseridos e envolvidos em ambientes que lidam com crianças e jovens. 
Posiciona-se ainda como uma ferramenta de significativo auxílio para pesquisas acadêmicas e para disciplinas ligadas aos estágios clínicos, uma vez que se destina a um público-alvo específico.

Faz-se necessário ressaltar que não se trata de um passo a passo que deve ser seguido à risca, e sim cumpre a função de subsidiar o atendimento infantil com estratégias que possam potencializar os efeitos clínicos adaptativos, tornando o atendimento clínico mais eficaz. 